OPEN ACCESS

Edited by:

Chang Zou,

Shenzhen People's Hospital, Jinan

University, China

Reviewed by:

Joseph Zaia,

Boston University, United States

Yongwei Zhang,

Albert Einstein College of Medicine,

United States

*Correspondence:

Shanzhi Wang

sxwang2@ualr.edu

Specialty section

This article was submitted to

Molecular and Cellular Oncology,

a section of the journal

Frontiers in Oncology

Received: 01 December 2019

Accepted: 29 June 2020

Published: 05 August 2020

Citation:

Yan Z and Wang S (2020)

Proteoglycans as Therapeutic Targets

in Brain Cancer:

Front. Oncol. 10:1358

doi: 10.3389/fonc.2020.01358

\section{Proteoglycans as Therapeutic Targets in Brain Cancer}

\author{
Zoya Yan ${ }^{1}$ and Shanzhi Wang ${ }^{2 *}$ \\ ${ }^{1}$ Horace Greeley High School, Chappaqua, NY, United States, ${ }^{2}$ Chemistry Department, University of Arkansas at Little Rock, \\ Little Rock, AR, United States
}

Proteoglycans (PGs) are heavily glycosylated diverse proteins consisting of a "core protein" covalently attached to glycosaminoglycans (GAGs) and present on the cell surface, extracellular matrix, and intracellular milieu. Extracellular proteoglycans play crucial roles in facilitating cell signaling and migration, interacting with growth factor receptors, intracellular enzymes, extracellular ligands, and matrix components, as well as structural proteins and promoting significant tumor-microenvironment interactions in cancerous settings. As a result of their highly regulated expression patterns, recent research has focused on the role of proteoglycans in the development of nervous tissue, such as their effect on neurite outgrowth, participation in the development of precursor cell types, and regulation of cell behaviors. The present review summarizes current progress for the studies of proteoglycan function in brain cancer and explains recent research involving brain glycoproteins as modulators of migration, cell adhesion, glial tumor invasion, and neurite outgrowth. Furthermore, we highlight the correlations between specific proteoglycan alterations and the suggested cancer-associated proteoglycans as novel biomarkers for therapeutic targets.

Keywords: proteoglycan, glycosaminoglycan, glioblastoma, brain cancer, biomarker, inflammation

\section{INTRODUCTION OF BRAIN CANCER}

Brain tumors are abnormal cell growths in the brain, though only malignant tumors are cancerous. There are two types of brain tumors: the primary brain tumor, which originates from and resides within the brain, and the secondary (metastatic) brain tumor, which originates from cancer outside of the central nervous system (CNS) then spreads into the brain. While primary tumors are the more frequent solid tumors in children, metastatic tumors are more commonly diagnosed in adult patients (1).

In recent decades, the worldwide brain tumor incidence rate has increased across all ages. The standardization of age in varying countries is between 0.01-12.7 in males and 0.01-10.7 in females per 100,000 people, with the highest incidence in northern Europe and the lowest in Africa (2). According to the Central Brain Tumor Registry of the United States (CBTRUS), the incidence rate of CNS tumors in the United States (23.03 per 100,000 cases for a total count of 392,982) incident tumors, of which 121,277 cases 
are malignant and 271,705 non-malignant) is lower in males (20.59 per 100,000 for 165,148 total cases) than in females ( 25.31 per 100,000 for 227,834 total cases) (3). In addition, in the United States, the 5-years survival rate following the diagnosis of a primary malignant CNS tumor is about 35\% (2008-2014 data) ${ }^{1}$. The mortality rate of CNS cancers is estimated at about 3.4 per 100,000 in the world (2).

Across all age groups, the most common brain tumors develop from glial cells, which are gliomas that encompass a large scope of tumors and can be classified into four grades as follows: grade I (pilocytic astrocytoma), grade II (diffuse astrocytoma), grade III (anaplastic astrocytoma), and grade IV (glioblastoma multiforme) (4). Grade III and IV are categorized as high-grade or malignant gliomas with extremely poor prognosis, with grade IV diagnoses (which account for half of primary brain tumors) seeing a 5 -years survival rate of $<10 \%$ (5). The most common intracranial tumors in adults are brain metastases, with over 150,000 cases in the United States alone. Despite the considerable effect of varying primary tumor types on the incidence of metastases, $8-10 \%$ of adults diagnosed with cancer will develop brain metastases (6).

Developing treatment for CNS cancer is one of the most exigent branches of study in oncology. Although therapeutic approaches that exploit the immune system are a promising alternative strategy to surgery, radiotherapy, and anticancer drug therapy, multidrug resistance is a substantial obstacle restricting the success of conventional chemotherapy (7). The innate chemoresistance of many primary brain tumors and insufficient penetration of cytotoxic drugs across the blood-brain barrier (BBB) are also both responsible for the unsuccessful response of brain tumors to chemotherapy (8). Due to the urgency for novel therapies that combat these occurrences, researchers have emphasized and prioritized the development of anticancer drugs.

Using in vitro methods, Kwon et al. directly tested the effects of sialic acid glycan and glycosylation on BBB influx and efflux of IgG, specifically the influx and efflux processes for $\mathrm{BBB}$ endothelial cells, and facilitated "direct measurement of the Permeability Coefficient in each direction" $(9,10)$. In the study, BBB pharmacokinetics were found to be considerably affected by modest changes of IgG glycan profiles with sialylated glycans, suggesting that modifying IgG glycan could become an effective technique in increasing the concentration of the brain's therapeutic antibodies. Because immune pathways induced by sialylated IgG cause little inflammation, sialylation may therefore suggest beneficial clinical possibilities and further implications for patients with other CNS diseases such as Alzheimer's disease (11-13).

\footnotetext{
Abbreviations: $\mathrm{BBB}$, blood-brain barrier; $\mathrm{CS}$, chondroitin sulfate; CNS, central nervous system; DS, dermatan sulfate; ECM, extracellular matrix; GAGs, glycosaminoglycans; GBM, glioblastoma; HS, heparan sulfate; HP, heparin; $\mathrm{HA}$, hyaluronic acid; KS, keratan sulfate; NG2, neuron-glial antigen 2; PG, proteoglycan.

${ }^{1}$ Available online at: https://www.cancer.org/content/dam/cancer-org/research/ cancer-facts-and-statistics/annual-cancer-facts-and-figures/2019/cancer-factsand-figures-2019.pdf
}

\section{ROLES OF PROTEOGLYCANS IN BRAIN CANCER}

Proteoglycans (PGs) are heavily glycosylated proteins and present on the cell surface, extracellular matrix (ECM), and intracellular milieu (14). The basic PG unit consists of a "core protein" covalently attached to glycosaminoglycans (GAGs), which are long chains consisting of linear or branched carbohydrate polymers that are negatively charged under certain physiological conditions, expressed on most mammalian cells. The six known GAGs are heparin (HP), hyaluronic acid (HA), heparan sulfate (HS), chondroitin sulfate (CS), keratan sulfate (KS), and dermatan sulfate (DS). These GAGs' respective disaccharide units contain different uronic and amino sugars (15). Their structure is demonstrated in Figure 1. GAGs are considerably linked to several diseases, including cancer, inflammation, bacterial infections, multiple sclerosis, viral infections, and Alzheimer's disease, as they interact with ligands to modulate physiological and pathological processes. Given such active involvement, GAG-based drugs are of considerable interest to researchers and have yielded promising outcomes in both animal and clinical trials, suggesting prospective development in therapeutics (16).

GAG to PG linkage is crucial to establishing and maintaining the fundamental functions of CNS, such as migration, cellular proliferation, specification, plasticity, synaptogenesis, and regeneration. Their mechanisms and functions have been summarized in many reviews (17-20). PG diversity depends on differential expression of protein sequences, variations in the length, and profile of GAG modifications. PGs regulate growth factors that affect cell adhesion, neurite outgrowth (21), ECM assembly, and tumor cell invasion (22, 23). Syndecans and glypicans are the two main transmembrane PGs containing HS chains in the CNS. Heparan sulfate PGs directly influence the aggregation and activity of AMPA receptors, which hinders cognitive functions by inducing or maintaining long-term potentiation (LTP) (24). Chondroitin sulfate PG, which is expressed abundantly in the cerebellum and hippocampus but decreases significantly postnatally, affects the stabilization of synapses and axonal sprouting (25). Figure 2 demonstrates the selected cellular localization and significance for tumor development of the PGs discussed.

\section{Chondroitin Sulfate Proteoglycan}

Chondroitin sulfate PG 4, commonly referred to as neuronglial antigen 2 (NG2), contributes to the stabilization of interaction between cell and substratum on endothelial basement membranes, especially at the early spreading stage of melanoma cells (26) In addition, CS PG 4 is a suggested biomarker in glioblastoma (GBM) (27). NG2-expressing oligodendrocyte precursor cells support neurons and synaptic signaling physiologically and carry out these functions in both brains that are healthy and those in the process of injury repair and regeneration. Moreover, NG2 protein facilitates tumorigenesis and tumor progression (28). In the previous study of human GBM cells, more cells survived under NG2-mediated 

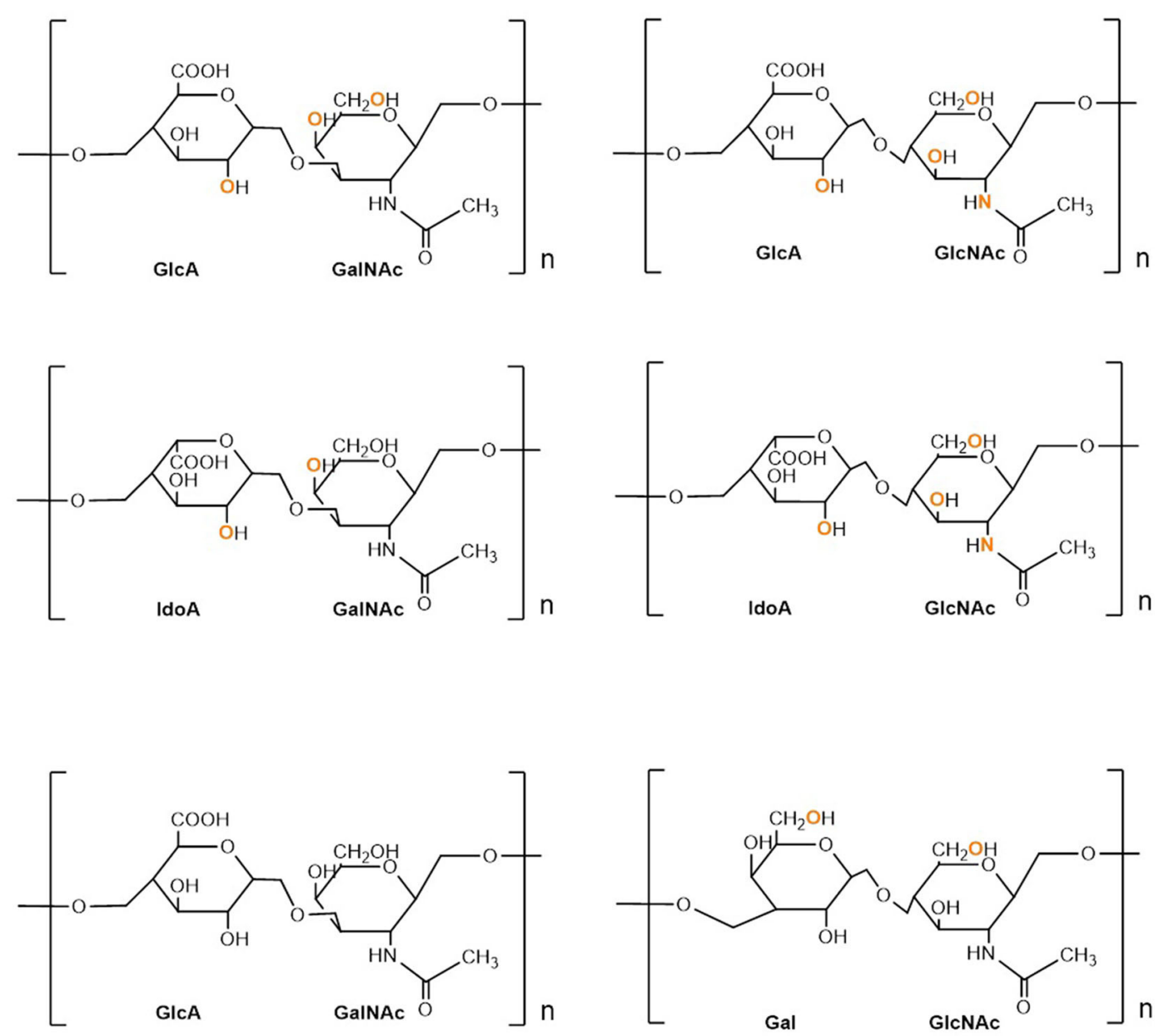

FIGURE 1 | Structure and composition of GAGs. Sulphation sites are shown in orange.

activation (29) and chemoresistance through integrin-dependent PI3K/Akt signaling (30).

Gliomagenesis is induced by unusual expression of neuronglial antigen 2 endocytosis in vivo murine oligodendrocyte precursor cells, which provides another mechanism through which benign precursor cells can be converted into cancer stem cells (31). Additionally, NG2-expressing precursor cells demonstrate significant developmental plasticity. For instance, activating Notch signaling induced pericyte-like differentiation in NG2-positive GBM cancer stem cells, which during tumor angiogenesis contributed to vessel stabilization (32). Although these results suggest that NG2 plays a role in cancer stem cells, it is still uncertain whether the GAG moieties or the PG's other functional domains are responsible for the stemnessrelated functions.

Lam et al. reported an efficient and effective "glial progenitor cell-based therapy" for congenital myelin CNS disorders (33). From bone marrow stromal cells, they produced glial progenitor cells in a 14-days CS PG 4-based induction protocol. The generated cells were highly enriched in oligodendrocyte precursor cell marker expression. After being transplanted into the myelin-deficient mice, the cells differentiated successfully into myelinogenic oligodendrocytes. Both lifespan and motor function were improved significantly by remyelination of the shiverer mouse. Their study demonstrated the feasibility of human bone marrow stromal cells as a source of glial progenitor cells for attaining such myelinogenic oligodendrocytes (33). The novel induction protocol overcame existing hurdles of cell source restriction and timeframe requirements, providing a method for efficient myelin disorder glial therapy.

In addition, lecticans were also investigated as a group of chondroitin sulfate PGs due to their role in linking ECM molecules (34). The unique composition of brain ECM causes brain tissue to resist invasion by non-neuronal tumors (35). Due to its moderate plasticity, CNS has a considerable capacity for regeneration, although changes in ECM have been observed after trauma and throughout the development of CNS disease. The modification of PGs in ECM is shown as one of the factors leading to change in CNS plasticity. Through control of neurotransmission and synaptic connections, the scaffold of proteins and sugars in the ECM changes the functionality of surrounding tissue (36).

To activate immune cells, CS PGs generally collect the microenvironment's signals and bind immunological receptors, 


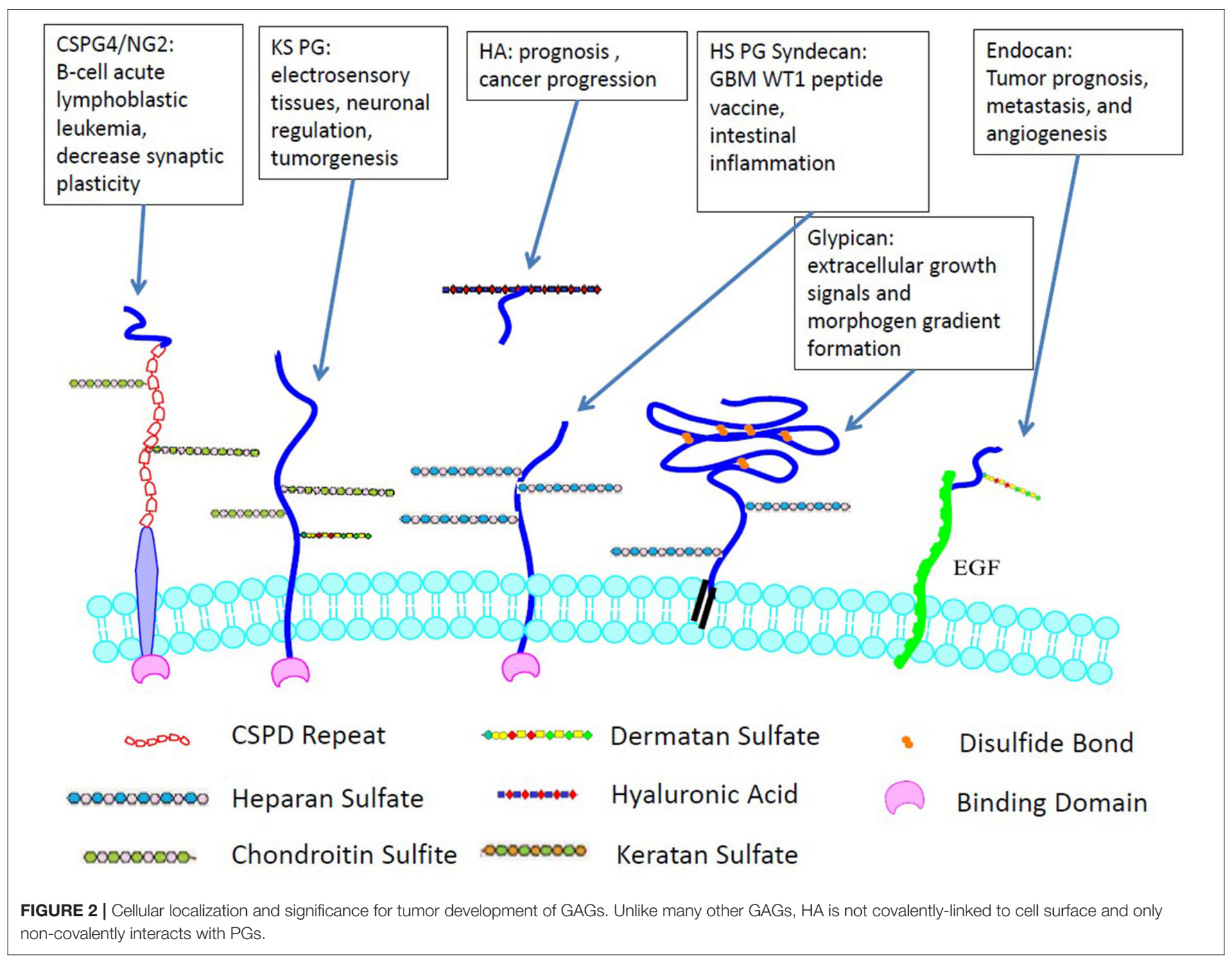

thus boosting inflammatory responses. CS PGs also stimulate matrix-degrading enzymes and bind signaling molecules in immune cells such as chemokines and cytokines (37).

\section{Heparan Sulfate Proteoglycans}

Heparin has anticoagulant activity and can only be produced by mast cells. Heparan sulfate also functions as an anticoagulant, though on a lower level than heparin, and is generated by nearly all cell types. Present both in the ECM and on the cell surface, heparan sulfate PGs (HSPG) facilitate cellmicroenvironment interactions and cell signaling pathways. In GBM, HS glycosaminoglycans expression and their regulating enzymes are changed, but the structure and content of the HS itself remain unknown. For example, glypicans of the HS PG families [See review: Wang et al. (38)] are proteins that are membrane-bound and that modulate morphogen gradient formation and extracellular growth signals to engage in organ development (39). Crucially, some studies reported an increased level of glypicans in the peripheral blood of patients, holding glypicans as a promising new biomarker in the cancer field (40).
Tran et al. used LC-MS analysis to portray the differences in both HS disaccharide content and structure. As a result, they suggested inter-tumoral differences in PG expression and function have potential implications for therapeutic stratification (41).

Spyrou studied the inhibition of heparanase in brain tumor cells of children and subsequently reduced their invasive capacity, proliferation, and tumor growth in vivo. The results suggest that heparanase affects both tumor cells and their ECM in cases of malignant brain tumors. However, the inhibitor (PG545) failed to pass the $\mathrm{BBB}$ due to its size, and thus direct injection or a new drug delivery system is required (42).

\section{Hyaluronic Acid}

Hyaluronan (or hyaluronic acid) is a "multifunctional GAG synthesized as a large negatively charged linear polymer by distinct hyaluronan synthases" (43). While aggrecan-related components generally result in clear regional distribution patterns, hyaluronan is widely distributed in the white and gray matter (44). HA interacts with several cell membrane receptors, including CD44 and Lymphatic vessel endothelial hyaluronan 
receptor 1, the former being the more thoroughly studied receptor for HA-mediated motility in cancer progression. In addition, certain PGs use link modules to form supramolecular complexes with HA. Generally, high levels of HA and HA receptors are correlated with poor prognosis in cancer patients.

Using pluripotent stem cells-derived and primary brain microvascular endothelial cells, Al-Ahmad et al. tested the effect of $\mathrm{HA}$ on $\mathrm{BBB}$ properties. The impact of $\mathrm{HA}$ signaling on developmental and mature brain microvascular endothelial cells was assessed by measuring changes in transendothelial electrical resistance, permeability, brain microvascular endothelial cells markers localization, and expression, CD44 expression, and hyaluronan levels. HA treatment generally reduced barrier function and P-glycoprotein activity. The effects were more evident with treatment using oligomeric forms of HA and exacerbated when the treatment was applied during the brain microvascular endothelial cells differentiation phase (considered developmental BBB). The hyaluronidase activity, as well as an increase in CD44 expression during prolonged oxygenglucose deprivation stress, were also observed. Inhibiting HA signaling by the antibody blockade of CD44 reversed the treatment's adverse effects, thus conveying the significance of HA signaling through CD44 on BBB properties (45). Moreover, Hartheimer et al. determined how hyaluronidases can sensitize GBM stem cells to chemotherapy drugs by disrupting the HA-CD44 signaling, with which they further developed a combined treatment of hyaluronidases and chemotherapy drugs by disrupting the stemness-promoting HA to target GBM stem cells. This combination therapy shows promise even when temozolomide treatment alone causes resistance (46).

\section{Dermatan Sulfate PG-Endocan: A New Biomarker and Therapeutic Target}

Endocan is a novel endothelial cell-specific molecule with $50 \mathrm{kDa}$ molecular weight and high solubility in water. As a proteoglycan, endocan is secreted into the blood and formed in the presence of CS. In normal tissues, CS and DS PGs are expressed in endothelial cells but are overexpressed in certain tumor endothelial cells. Unsurprisingly, abnormal expression levels of endocan were observed in tumor prognosis, angiogenesis, and metastasis. Researchers believe that the role of endocan is to regulate the tumor by tumor-related angiogenesis, cell inflammation, lymphangiogenesis, and other aspects (47). Accordingly, Kijima et al. studied surface marks from patient derived xenografts and cell lines based on array comparative genomic hybridization to investigate the early stages of GBM tumorigenesis (48). In additional to research that found raised levels of systemic inflammatory markers to be correlated with cardiovascular disease (49), a recent study revealed that the specific sulfation level of DS is crucial in synaptic plasticity and is related to changes in the expression of glutamate receptors and other associated synaptic proteins (50). As such, endocan became a valuable target for GBM diagnosis and therapy.

As another interesting target, dermatan sulfate epimerase 1 is overexpressed in many types of cancer as a tumor-rejection antigen. The CS/DS chains mediate several growth factor signals. However, investigating their roles in gliomas involves less work. Liao et al. examined the expression of Dermatan sulfate epimerase 1 in gliomas by utilizing a public database and conducting immunohistochemistry on a tissue array. Their investigation revealed that Dermatan sulfate epimerase 1 regulates the HB-EGF/ErbB pathway, which participates in GBM cells' malignant behavior. Treating epidermal growth factor receptor and ErbB2 with selected inhibitors thus suppressed malignant phenotypes, demonstrating that the upregulation of Dermatan sulfate epimerase in gliomas contributes to controlling malignant behavior in cancer cells (51).

\section{Keratan Sulfate (KS)}

Keratan sulfate (KS) is a sulfated GAG, which contains structurally unique characteristics of diversity in the linker oligosaccharides connecting to the core protein. The repeating disaccharide unit in $\mathrm{KS}$ contains one galactose and one $\mathrm{N}$ acetylglucosamine and is linked to core proteins via either $\mathrm{N}$-linked or O-linked glycosylation of the PGs. KS is most abundant in the cornea, and second abundant in the brain (52). Negatively charged KS modifications of synaptic vesicle protein 2 interacted with both $\mathrm{Ca}^{2+}$ ions and other neurotransmitters such as dopamine, establishing the PG delivery complex (53). Furthermore, high sulfation level KS PGs are commonly found in the brain. For example, synaptic vesicle proteins 2 played significant neuronal and synaptic regulatory roles (54).

An earlier study reported that highly sulfated KS was overexpressed in malignant astrocytic tumors (55). It has also been found that the interruption of Synaptic vesicle proteins 2 functionality is associated with epilepsy (56). These results were confirmed by the subsequent research of the interactivity of KS with nerve growth factor and receptor proteins, neuroregulatory proteins, synaptic proteins and neurotransmitters (57). In addition, abnormal sulfation degrees of KS are observed in the brains of Alzheimer's patients (58). Tsidulko's work demonstrated that PG composition and ECM structure in normal brain tissue were affected during temozolomide induced chemotherapy. These changes were believed to participate in the development of the tumorigenic niche for the expansion of the residual glioma cells and the disease progression (59). Recently, researchers have reviewed the influences of KS sulfation on electrosensory tissues and neuronal regulation. KS with overexpressed sulfation level interacts with neuroregulatory proteins. Hence, actin and tubulin cytoskeletal development was stabilized by KS PG microtubuleassociated proteins during neuritogenesis (60).

\section{THE ROLE OF PGs IN BRAIN INFLAMMATION AND PLASTICITY}

In general, PGs have influenced several aspects of tumor biology such as tumor cell adhesion and migration, cell proliferation, angiogenesis, and inflammation. Up- and downregulated expression in PG core proteins is observed in many cancers and usually related to changes in cell signaling and invasion $(19,61)$. Jang et al. found that the interaction between the intracellular domain of some transmembrane PGs with the 
cytoplasmic domain of proteins promoted the signaling (62). In an earlier review, the cytoplasmic domain of syndecan-1 was found to have interaction with talin to modulate integrin signaling via a syndecan-1-integrin-insulin-like complex (63). Likewise, the cytoplasmic tail of transmembrane heparan sulfate PG syndecan- 4 interacts with $\alpha$-actinin regulating cytoskeletal organization. Fröhling et al.' recent research suggested that the loss of syndecan-4 expression is correlated with the increase if intestinal inflammation. While primarily expressed in the colonic epithelium, syndecan-4 accumulated the deficiency during the growth of susceptibility regarding the intestinal inflammation. Mechanisms were proposed that syndecan-4 played a role in protecting against inflammation, keeping the epithelial gut barrier's unity and regeneration (64). When using anti-syndecan4 antibodies as a therapeutic approach to treat patients with inflammatory disorders, researchers must carefully evaluate patients who have inflammatory diseases associated with an epithelial barrier function.

Many PGs were proposed as markers for therapy evaluation. For example, syndecan-4 mRNA expression was specified as the unique marker to predict the GBM multiforme patient's response during the WT1 peptide vaccine treatment (65). Letoha et al. reported that syndecan- 4 bound and mediated the transfer of a cell-penetrating short peptide with 17 amino acids into the cells (66). Roy et al. then demonstrated a positive correlation between glioma grade and serglycin expression level in GBM progression (67).

There is significant evidence showing that the sulfate composition of CS GAG chains changes with age. As a result of aging and aggregation of proteins, the deposition of HS PGs and CS PGs results in the injury of protective perineuronal nets with increased cell death (60). Dying neurons then induce inflammation, ECM degrades through the proteolytic activity of enzymes, inducing responses that amplify neuronal death and neuroinflammation (68). Simultaneously, overexpression of chondroitin 6-O-sulfotransferase 1 may decrease the ratio of 4$6 \mathrm{~S}$ in perineuronal nets and increase seizure susceptibility (69). This is supported by Foscarin's work that the age-associated rise in the ratio of 4-6S GAG in perineuronal nets may decrease synaptic plasticity (70). Their studies highlighted the necessity for genetic manipulation of other enzymes such as chondroitin

\section{REFERENCES}

1. Louis DN, Ohgaki H, Wiestler OD, Cavenee WK, Burger PC, Jouvet A, et al. The WHO classification of tumours of the central nervous system. Acta Neuropathol. (2007) 114:97-109. doi: 10.1007/s00401-007-0243-4

2. Kalan Farmanfarma KH, Mohammadian M, Shahabinia Z, Hassanipour S, Salehiniya H. Brain cancer in the world: an epidemiological review. World Cancer Res J. (2019) 6:E1356. doi: 10.32113/wcrj_20197_1356

3. Ostrom QT, Gittleman H, Truitt G, Boscia A, Kruchko C, Barnholtz-Sloan JS. CBTRUS statistical report: primary brain and other central nervous system tumors diagnosed in the United States in 2011-2015. Neuro Oncol. (2018) 20(suppl.4):iv1-86. doi: 10.1093/neuonc/noy131

4. Wesseling P, Capper D. WHO (2016) classification of gliomas. Neuropathol Appl Neurobiol. (2018) 44:139-50. doi: 10.1111/nan. 12432 sulfotransferases to discover their biological functions and generate the profile of sulfation's role in development and aging.

Recent preclinical research demonstrated the antitumoral effects of chondroitin sulfate PG 4. The NG2-directed chimeric antigen receptor T-cells were proved to efficiently target GBM cancer stem cells (71). The combination of anti-NG2 antibodies was induced in chemotherapy in B-cell acute lymphoblastic leukemia (72).

\section{CONCLUSION}

In summary, adjustments in PG core proteins, biosynthetic enzymes, and extracellular regulating enzymes are correlated with many developmental anomalies and overgrowth or tumor predisposition syndromes. PGs facilitate the activity of various signaling pathways and stimulate cell-microenvironment interactions in tumors. Due to such a diverse range of functions, PGs and their modifying enzymes are an imperative area of study that may potentially uncover therapeutic targets and biomarkers of GBM. In the damaged CNS, PGs accumulate during traumatic brain injuries, multiple sclerosis, and spinal cord injuries, driving pathogenesis and neuroinflammation. It should be noted that compared to the in vitro examination, more complex factors may interfere with the regulated expression of PGs in ECM in vivo. When assessing experiment data for therapeutic targets and treatment strategies, researchers should carefully consider adverse side effects that can be avoided in advance.

\section{AUTHOR CONTRIBUTIONS}

All authors participated in writing and revising the manuscript.

\section{FUNDING}

This work has been supported by UA Little Rock Startup Grant.

\section{ACKNOWLEDGMENTS}

We wish to acknowledge the support of UA Little Rock for the Startup Package.
5. Wilson TA, Karajannis MA, Harter DH. Glioblastoma multiforme: state of the art and future therapeutics. Surg Neurol Int. (2014) 5:64. doi: 10.4103/2152-7806.132138

6. Ferguson SD, Everson RG, Wagner KM, Yeboa DN, McCutcheon IE, Sawaya R. Neurosurgical 31 brain metastases. Adult CNS Radiat Oncol. (2018) 27:431. doi: 10.1007/978-3-319-42878-9_31

7. Liu C, Zong H. Developmental origins of brain tumors. Curr Opin Neurobiol. (2012) 22:844-9. doi: 10.1016/j.conb.2012.04.012

8. Regina A, Demeule M, Laplante A, Jodoin J, Dagenais C, Berthelet F, et al. Multidrug resistance in brain tumors: roles of the blood-brain barrier. Cancer Metastasis Rev. (2001) 20:13-25. doi: 10.1023/a:1013104423154

9. Kwon H, Crisostomo AC, Smalls HM, Finke JM. Anti- $\alpha \beta$ oligomer IgG and surface sialic acid in intravenous immunoglobulin: measurement and correlation with clinical outcomes in Alzheimer's disease treatment. PLoS ONE. (2015) 10:e0120420. doi: 10.1371/journal.pone.0120420 
10. Finke JM, Ayres KR, Brisbin RP, Hill HA, Wing EE, Banks WA. Antibody blood-brain barrier efflux is modulated by glycan modification. Biochim Biophys Acta. (2017) 1861:2228-39. doi: 10.1016/j.bbagen.2017.06.008

11. Alter G, Ottenhoff TH, Joosten SA. Antibody glycosylation in inflammation, disease and vaccination. InSeminars Immunol. (2018) 39:102-10. doi: 10.1016/j.smim.2018.05.003

12. Ravetch JV, Kaneko Y, Nimmerjahn F. Polypeptides With Enhanced AntiInflammatory And Decreased Cytotoxic Properties And Relating Methods. United States patent application US 16/150,058. New York, NY: US patent (2019).

13. Zhou X, Kinlough CL, Hughey RP, Jin M, Inoue H, Etling E, et al. Sialylation of MUC4 $\beta$ N-glycans by ST6GAL1 orchestrates human airway epithelial cell differentiation associated with type-2 inflammation. JCI insight. (2019) 4:e122475. doi: 10.1172/jci.insight. 122475

14. Bedini E, Corsaro MM, Fernández-Mayoralas A, Iadonisi A. Chondroitin, dermatan, heparan, and keratan sulfate: structure and functions. In: E Cohen, H Merzendorfer, editors. Extracellular Sugar-Based Biopolymers Matrices. Biologically-Inspired Systems. Cham: Springer (2019).

15. Aquino RS, Park PW. Glycosaminoglycans and infection. Front Biosci. (2016) 21:1260-77. doi: 10.2741/4455

16. Morla S. Glycosaminoglycans and glycosaminoglycan mimetics in cancer and inflammation. Int J Mol Sci. (2019) 20:1963. doi: 10.3390/ijms20081963

17. Vitale D, Kumar Katakam S, Greve B, Jang B, Oh E-S, Alaniz L, et al. Proteoglycans and glycosaminoglycans as regulators of cancer stem cell function and therapeutic resistance. FEBS J. (2019) 286:287082. doi: $10.1111 /$ febs. 14967

18. Karamanos NK, Piperigkou Z, Theocharis AD, Watanabe H, Franchi M, Baud S, et al. Proteoglycan chemical diversity drives multifunctional cell regulation and therapeutics. Chem Rev. (2018) 118:9152-232. doi: 10.1021/acs.chemrev.8b00354

19. Wade A, Robinson AE, Engler JR, Petritsch C, David James C, Phillips JJ. Proteoglycans and their roles in brain cancer. FEBS J. (2013) 280:2399417. doi: $10.1111 /$ febs. 12109

20. Quirico-Santos T, Fonseca CO, Lagrota-Candido L. Brain sweet brain: importance of sugars for the cerebral microenvironment and tumor development. Arq Neuropsiquiatr. (2010) 68:799803. doi: 10.1590/S0004-282X2010000500024

21. Kanai MI, Kim MJ, Akiyama T, Takemura M, Wharton K, O'Connor MB, et al. Regulation of neuroblast proliferation by surface glia in the Drosophila larval brain. Sci Rep. (2018) 8:3730. doi: 10.1038/s41598-018-22028-y

22. Walker C, Mojares E, del Río Hernández A. Role of extracellular matrix in development and cancer progression. Int J Mol Sci. (2018) 19:3028. doi: 10.3390/ijms19103028

23. Ferrer VP, Moura Neto V, Mentlein R. Glioma infiltration and extracellular matrix: key players and modulators. Glia. (2018) 66:1542-65. doi: 10.1002/glia.23309

24. Holmes BB, DeVos SL, Kfoury N, Li M, Jacks R, Yanamandra K, et al. Heparan sulfate proteoglycans mediate internalization and propagation of specific proteopathic seeds. Proc Natl Acad Sci USA. (2013) 110:E313847. doi: 10.1073/pnas.1301440110

25. Sim H, Hu B, Viapiano MS. Reduced expression of the hyaluronan and proteoglycan link proteins in malignant gliomas. J Biol Chem. (2009) 284:26547-56. doi: 10.1074/jbc.M109.013185

26. Finocchiaro G, Pellegatta S. NG2/CSPG4 in glioblastoma: about flexibility, Neuro-Oncology. (2019) 21:697-8. doi: 10.1093/neuonc/noz055

27. Svendsen A, Verhoeff JJ, Immervoll H, Brøgger JC, Kmiecik J, Poli A, et al. Expression of the progenitor marker NG2/CSPG4 predicts poor survival and resistance to ionising radiation in glioblastoma. Acta Neuropathol. (2011) 122:495-510. doi: 10.1007/s00401-011-0867-2

28. Yadavilli S, Hwang EI, Packer RJ, Nazarian J. The role of NG2 proteoglycan in glioma. Transl Oncol. (2016) 9:57-63. doi: 10.1016/j.tranon.2015.12.005

29. Downward J. PI 3-kinase, Akt and cell survival. Semin Cell Dev Biol. (2004) 15:177-82. doi: 10.1016/j.semcdb.2004.01.002

30. Chekenya M, Krakstad C, Svendsen A, Netland IA, Staalesen V, Tysnes $\mathrm{BB}$, et al. The progenitor cell marker NG2/MPG promotes chemoresistance by activation of integrin-dependent PI3K/Akt signaling. Oncogene. (2008) 27:5182-94. doi: 10.1038/onc.2008.157
31. Daynac M, Chouchane M, Collins HY, Murphy NE, Andor N, Niu J, et al. Lgl1 controls NG2 endocytic pathway to regulate oligodendrocyte differentiation and asymmetric cell division and gliomagenesis. Nat Commun. (2018) 9:2862. doi: 10.1038/s41467-018-05099-3

32. Guichet PO, Guelfi S, Teigell M, Hoppe L, Bakalara N, Bauchet L, et al. Notch1 stimulation induces a vascularization switch with pericyte-like cell differentiation of glioblastoma stem cells. Stem Cells. (2015) 33:2134. doi: 10.1002/stem.1767

33. Lam G, Shea GK, Wu LK, Sui LMT, Hei KC, Yin YWC, et al. Neuron-Glial Antigen 2 (NG2)-based Glial Induction of Human BMSCs: a fast \& safe glial progenitor cell-based therapy for congenital myelin disorders of the central nervous system. bioRxiv. (2019) 658997. doi: 10.1101/658997

34. Yamaguchi Y. Lecticans: organizers of the brain extracellular matrix. Cell Mol Life Sci. (2000) 57:276-89. doi: 10.1007/PL00000690

35. Veillon L, Fakih C, Abou-El-Hassan H, Kobeissy F, Mechref Y. Glycosylation changes in brain cancer. ACS Chem Neurosci. (2017) 9:51-72. doi: 10.1021/acschemneuro.7b00271

36. Warren PM, Dickens SM, Gigout S, Fawcett JW, Kwok JC. Regulation of CNS plasticity through the extracellular matrix. In: The Oxford Handbook of Developmental Neural Plasticity. New York, NY: Oxford University Press (2018). doi: 10.1093/oxfordhb/9780190635374.013.11

37. Stephenson EL, Yong VW. Pro-inflammatory roles of chondroitin sulfate proteoglycans in disorders of the central nervous system. Matrix Biol. (2018) 71:432-42. doi: 10.1016/j.matbio.2018.04.010

38. Qiao D, Meyer K, Mundhenke C, Drew SA, Friedl A. Heparan sulfate proteoglycans as regulators of fibroblast growth Factor-2 signaling in brain endothelial cells. J Biol Chem. (2003) 278:16045-53. doi: 10.1074/jbc.M211259200

39. Sarrazin S, Lamanna WC, Esko JD. Heparan sulfate proteoglycans. Cold Spring Harbor Perspectiv Biol. (2011) 3:a004952. doi: 10.1101/cshperspect.a004952

40. Nagarajan A, Malvi P, Wajapeyee N. Heparan sulfate and heparan sulfate proteoglycans in cancer initiation and progression. Front Endocrinol. (2018) 9:483. doi: 10.3389/fendo.2018.00483

41. Tran VM, Wade A, McKinney A, Chen K, Lindberg OR, Engler JR, et al. Heparan sulfate glycosaminoglycans in glioblastoma promote tumor invasion. Mol Cancer Res. (2017) 15:1623-33. doi: 10.1158/1541-7786.MCR-17-0352

42. Spyrou A, Kundu S, Haseeb L, Yu D, Olofsson T, Dredge K, et al. Inhibition of heparanase in pediatric brain tumor cells attenuates their proliferation, invasive capacity, and in vivo tumor growth. Mol Cancer Therapeutics. (2017) 16:1705-16. doi: 10.1158/1535-7163.MCT-16-0900

43. Park JB, Kwak HJ, Lee SH. Role of hyaluronan in glioma invasion. Cell Adh Migr. (2008) 2:202-7. doi: 10.4161/cam.2.3.6320

44. Bonneh-Barkay D, Wiley CA. Brain extracellular matrix in neurodegeneration. Brain Pathol. (2009) 19:57385. doi: 10.1111/j.1750-3639.2008.00195.x

45. Al-Ahmad AJ, Patel R, Palecek SP, Shusta EV. Hyaluronan impairs the barrier integrity of brain microvascular endothelial cells through a CD44-dependent pathway. J Cerebral Blood Flow Metab. (2019) 39:175975. doi: 10.1177/0271678X18767748

46. Hartheimer JS, Park S, Rao SS, Kim Y. Targeting hyaluronan interactions for glioblastoma stem cell therapy. Cancer Microenvironment. (2019) 12:4756. doi: 10.1007/s12307-019-00224-2

47. Yang J, Yang Q, Yu S, Zhang X. Endocan: a new marker for cancer and a target for cancer therapy. Biomed Rep. (2015) 3:279-83. doi: 10.3892/br.2015.438

48. Kijima N, Kanematsu D, Shofuda T, Nonaka M, Iwata R, Fukai $\mathrm{J}$, et al. TMOD-01 characterization of patient-derived primary cell lines and xenografts for glioblastoma. Neuro-Oncology. (2019) 21(Suppl.6):vi262. doi: 10.1093/neuonc/noz175.1100

49. Zhao $\mathrm{T}$, Kecheng $\mathrm{Y}$, Zhao $\mathrm{X}, \mathrm{Hu} \mathrm{X}$, Zhu J, Wang $\mathrm{Y}$, et al. The higher serum endocan levels may be a risk factor for the onset of cardiovascular disease: a meta-analysis. Medicine. (2018) 97:e13407. doi: 10.1097/MD.0000000000013407

50. Li Q, Wu X, Wu Q, Ge B, Guo X, Ntim M, et al. Impaired cognitive function and altered hippocampal synaptic plasticity in mice lacking dermatan sulfotransferase Chst14/D4st1. Front Mol Neurosci. (2019) 12:26. doi: 10.3389/fnmol.2019.00026 
51. Liao WC, Liao CK, Tsai YH, Tseng T-J, Chuang L-C, Lan C-T, et al. DSE promotes aggressive glioma cell phenotypes by enhancing HB-EGF/ErbB signaling. PLoS ONE. (2018) 13:e0198364. doi: 10.1371/journal.pone.0198364

52. Ohmae M, Yamazaki Y, Sezukuri K, Takada J. Keratan sulfate, a "unique" sulfo-sugar: structures, functions, and synthesis. Trends Glycosci Glycotechnol. (2019) 31:E129-36. doi: 10.4052/tigg.1830.1E

53. Caterson B, Melrose J. Keratan sulfate, a complex glycosaminoglycan with unique functional capability. Glycobiology. (2018) 28:182206. doi: 10.1093/glycob/cwy003

54. Jia M, Travaglia A, Pollonini G, Fedele G, Alberini CM. Developmental changes in plasticity, synaptic, glia, and connectivity protein levels in rat medial prefrontal cortex. Learning Memory. (2018) 25:533-43. doi: 10.1101/lm.047753.118

55. Kato Y, Hayatsu N, Kaneko MK, Ogasawara S, Hamano T, Takahashi S, et al. Increased expression of highly sulfated keratan sulfate synthesized in malignant astrocytic tumors. Biochem Biophys Res Commun. (2008) 369:10416. doi: 10.1016/j.bbrc.2008.02.130

56. Wan QF, Zhou ZY, Thakur P, Vila A, Sherry DM, Janz R, et al. SV2 acts via presynaptic calcium to regulate neurotransmitter release. Neuron. (2010) 66:884-95. doi: 10.1016/j.neuron.2010.05.010

57. Conrad AH, Zhang Y, Tasheva ES, Conrad GW. Proteomic analysis of potential keratan sulfate, chondroitin sulfate, A., and hyaluronic acid molecular interactions. Invest Ophthalmol Vis Sci. (2010) 51:450015. doi: 10.1167/iovs.09-4914

58. Zhang Z, Takeda-Uchimura Y, Foyez T, Ohtake-Niimi S, Narentuya Akatsu $\mathrm{H}$, Nishitsuji K, et al. Deficiency of a sulfotransferase for sialic acid-modified glycans mitigates Alzheimer's pathology. Proc Natl Acad Sci USA. (2017) 114:E2947-54. doi: 10.1073/pnas.1615036114

59. Tsidulko AY, Bezier C, de La Bourdonnaye G, Suhovskih AV, Pankova TM, Kazanskaya GM, et al. Conventional anti-glioblastoma chemotherapy affects proteoglycan composition of brain extracellular matrix in rat experimental model in vivo. Front Pharmacol. (2018) 9:1104. doi: 10.3389/fphar.2018.01104

60. Melrose J. Functional consequences of keratan sulfate sulfation in electrosensory tissues and in neuronal regulation. Adv Biosystems. (2019) 3:1800327. doi: 10.1002/adbi.201800327

61. Nikitovic D, Berdiaki A, Spyridaki I, Krasanakis T, Tsatsakis A, Tzanakakis GN. Proteoglycans-biomarkers and targets in cancer therapy. Front Endocrinol. (2018) 9:69. doi: 10.3389/fendo.2018.00069

62. Jang B, Jung H, Hong H, Oh ES. Syndecan transmembrane domain modulates intracellular signalling by regulating the oligomeric status of the cytoplasmic domain. Cell Signalling. (2018) 52:121-6. doi: 10.1016/j.cellsig.2018.09.003

63. Stepp MA, Pal-Ghosh S, Tadvalkar G, Pajoohesh-Ganji A. Syndecan1 and its expanding list of contacts. Adv Wound Care. (2015) 4:23549. doi: 10.1089/wound.2014.0555
64. Fröhling M, Tepasse P, Intemann J, Sambale M, Sherwood J, Paruzel P, et al. Syndecan-4 modulates epithelial gut barrier function and epithelial regeneration in experimental colitis. Inflamm Bowel Dis. (2018) 24:257989. doi: $10.1093 /$ ibd/izy 248

65. Takashima S, Oka Y, Fujiki F, Morimoto S, Nakajima H, Nakae Y, et al. Syndecan-4 as a biomarker to predict clinical outcome for glioblastoma multiforme treated with WT1 peptide vaccine. Future Sci. (2016) 2:FSO96. doi: 10.4155/fsoa-2015-0008

66. Letoha T, Keller-Pintér A, Kusz E, Kolozsi C, Bozsó Z, Tóth G, et al. Cell-penetrating peptide exploited syndecans. Biochim Biophys Acta. (2010) 1798:2258-65. doi: 10.1016/j.bbamem.2010.01.022

67. Roy A, Attarha S, Weishaupt H, Edqvist PH, Swartling FJ, Bergqvist M, et al. Serglycin as a potential biomarker for glioma: association of serglycin expression, extent of mast cell recruitment and glioblastoma progression. Oncotarget. (2017) 8:24815. doi: 10.18632/oncotarget.15820

68. Candelario-Jalil E, Yang Y, Rosenberg GA. Diverse roles of matrix metalloproteinases and tissue inhibitors of metalloproteinases in neuroinflammation and cerebral ischemia. Neuroscience. (2009) 158:983-94. doi: 10.1016/j.neuroscience.2008.06.025

69. Yutsudo N, Kitagawa H. Involvement of chondroitin 6sulfation in temporal lobe epilepsy. Exp Neurol. (2015) 274:12633. doi: 10.1016/j.expneurol.2015.07.009

70. Foscarin S, Raha-Chowdhury R, Fawcett JW, Kwok JC. Brain ageing changes proteoglycan sulfation, rendering perineuronal nets more inhibitory. Aging. (2017) 9:1607. doi: 10.18632/aging.101256

71. Beard RE, Zheng Z, Lagisetty KH, Burns WR, Tran E, Hewitt SM, et al. Multiple chimeric antigen receptors successfully target chondroitin sulfate proteoglycan 4 in several different cancer histologies and cancer stem cells. J Immunother Cancer. (2014) 2:25. doi: 10.1186/2051-1426-2-25

72. Lopez-Millan B, Sanchez-Martinez D, Roca-Ho H, Gutierrez-Aguera F, Molina O, Diaz de la Guardia R, et al. NG2 antigen is a therapeutic target for MLL-rearranged B-cell acute lymphoblastic leukemia. Leukemia. (2019) 33:1557-69. doi: 10.1038/s41375-018-0353-0

Conflict of Interest: The authors declare that the research was conducted in the absence of any commercial or financial relationships that could be construed as a potential conflict of interest.

Copyright (C) 2020 Yan and Wang. This is an open-access article distributed under the terms of the Creative Commons Attribution License (CC BY). The use, distribution or reproduction in other forums is permitted, provided the original author(s) and the copyright owner(s) are credited and that the original publication in this journal is cited, in accordance with accepted academic practice. No use, distribution or reproduction is permitted which does not comply with these terms. 